\title{
Respiratory and Internal Unit Muscle Training in Diaphragmatic Thickness and Mobility and Lombar Stability of Pregnant Women: Case Study
}

\author{
Nathalia S. Abreu-Freire ${ }^{1,2 *}$, Fernanda N. Teixeira², Marcela M. Trogo², Raíra M. Ramos' \\ Gustavo B. Camilo², Bruno R. Dornelas',2, Liliana F. Oliveira', \\ ${ }^{1}$ Physiotherapy Course, Faculty of Medical and Health Sciences, Juiz de Fora, Minas Gerais, Brazil \\ ${ }^{2}$ Therezinha de Jesus Hospital and Maternity Hospital, Juiz de Fora, Brazil \\ Email: ^nathyfst@gmail.com
}

How to cite this paper: Abreu-Freire, N.S., Teixeira, F.N., Trogo, M.M., Ramos, R.M., Camilo, G.B., Dornelas, B.R. and Oliveira, L.F. (2021) Respiratory and Internal Unit Muscle Training in Diaphragmatic Thickness and Mobility and Lombar Stability of Pregnant Women: Case Study. Open Access Library Journal, 8: e7083.

https://doi.org/10.4236/oalib.1107083

Received: December 15, 2020

Accepted: January 11, 2021

Published: January 14, 2021

Copyright $\odot 2021$ by author(s) and Open Access Library Inc.

This work is licensed under the Creative Commons Attribution International License (CC BY 4.0).

http://creativecommons.org/licenses/by/4.0/

\begin{abstract}
Introduction: During pregnancy there are changes in the female body mediated by hormones that determine the need for new postural adjustments to compensate for the change in the center of gravity. Such adjustments tend to negatively impact the stabilizing function of the lower trunk, predisposing to dysfunction in the spine, pelvic floor and respiratory pattern. Objective: To evaluate the effects of respiratory muscle training and internal unit on the thickness and diaphragmatic mobility and lumbar stability of pregnant women. Methods: Experimental and controlled clinical trial involving women with gestational age ranging from 12 to 32 weeks. The volunteers were submitted to postural evaluation, ultrasonography of the diaphragm and evaluation of inspiratory and maximal expiratory pressure through the manovacuometer before the first and after the last session. Respiratory muscle training was performed using the IMT and PEP threshold and lumbar and pelvic stabilization exercises. Results: Ten pregnant women were eligible and two participated in all stages of the study. Ultrasonographic images showed increased mobility and thickness of the diaphragm on inspiration and expiration. The maximal inspiratory and expiratory pressure, measured by means of the manovacuometry, showed an increase in post-intervention values when compared to the initial evaluation. Postoperative postural assessment showed lumbar lordosis exacerbation and increased abdominal volume consistent with increased gestational age. Conclusion: The results of the present study allow us to conclude that respiratory muscle training associated with internal unit training had positive repercussions on the thickness and diaphragmatic mobility, as well as on the lumbar stability of the pregnant women who con-
\end{abstract}


cluded all the steps of this research.

\section{Subject Areas}

Gynecology \& Obstetrics

\section{Keywords}

Pregnant, Breathing Exercises, Respiratory Muscle Training, Muscular Training Breathing, Posture

\section{Introduction}

Pregnancy is a period of hormone-mediated transformations, with a significant impact on emotional and physical aspects. In this context, pregnant women may experience exercise intolerance and postural deviations associated with complaints of pain and dyspnea (Constantine et al., 2014 [1]; Jensen et al., 2008 [2]), and it is desirable to monitor health professionals throughout the pre-natural aiming to alleviate physical discomforts, especially those related to respiratory dysfunctions and the precarious spine stability (Metha et al., 2015) [3].

Spine stabilization refers to the interaction of the passive, active and neural systems. The passive system includes bone, joint and ligament structures responsible for passive stability. The neural system, composed of the central and peripheral nervous system, determines muscle activity. The active system comprises muscles and tendons that provide dynamic stability (Panjabi et al., 1992 [4]; Silveira et al., 2018 [5]).

During pregnancy, due to the growth of the uterus, an increase of four to five centimeters in the resting position of the diaphragm and an increase in the anteroposterior diameter of the chest are observed, resulting in less diaphragmatic mobility and consequent alteration of respiratory mechanics (Lemos et al., 2011) [6]. Several instruments are used by the physiotherapist to assess the respiratory system, among which the manovacuometer stands out, capable of measuring the maximum inspiratory (Pimax) and expiratory (Pmax) pressures. These variables refer to the muscular strength of the diaphragm, intercostal and abdominal muscles (Marcos, 2007 [7]; Onaga et al., 2009) [8].

Regarding the diaphragm, its importance is also evident in body stability, whose function it exercises in partnership with the pelvic floor, transverse abdomen and multifidus muscles. Such muscles were a functional complex called an internal unit (Shouchrad, 1980 [9]; Sartor et al., 2015) [10].

Lumbar multifiduses (ML) are deep and monoarticular, produce rapid and forced movements and have great resistance to fatigue, being able to stabilize the spine for long periods of time (Urquhart et al., 2005) [11]. They provide physiological rigidity and movement control, contributing $2 / 3$ of the increase in segmental rigidity resulting from contraction, as long as there is no injury and or 
local pain (França et al., 2008) [12].

The transverse abdomen (TA) is positioned in the deepest part of the lateral and anterior region of the lower trunk. Its function is to contract and tense the abdominal wall, providing local stability, even during movements of the upper and lower limbs (Stenes et al., 2007) [13].

As for the pelvic floor muscles (MAP), they are located in the lower portion of the abdominal-pelvic cavity and have the function of visceral support and maintaining urethral and anal closure pressure during effort (Metring et al., 2014) [14].

No publications were identified on expiratory and inspiratory muscle training and the internal unit in pregnant women and their effects on the diaphragm and lumbar spine stability. Believing that this training association can have a favorable impact on respiratory capacity and postural alignment, reducing respiratory dysfunctions and pain complaints, this study was structured, which aims to evaluate the effect of respiratory muscle training and the internal unit on diaphragmatic thickness and mobility and in the lumbar stability of pregnant women.

\section{Methods}

\subsection{Study Design, Research Period and Ethical Aspects}

Experimental and controlled study, conducted entirely in a public hospital in the city of Juiz de Fora-MG in the months of May and June 2019. The research was previously approved by the Research Ethics Committee (opinion number $3,352,500)$. All volunteers signed an informed consent form.

\subsection{Eligibility, Inclusion and Exclusion Criteria}

The sample was selected for convenience. Pregnant women attended at the gynecology and obstetrics service of the Hospital e Maternidade Terezinha de Jesus from 7 to 10 May 2019, in the afternoon, were eligible. Only those aged between 18 and 35 years, with 12 to 32 weeks of gestational age, with no report of cardiovascular pathologies and or diabetes mellitus and who accepted to participate in the research were included. Pregnant women undergoing treatment for postural deviations associated or not with spinal pain were excluded.

\subsection{Outcomes, Evaluation Procedures and Research Protocol}

Figure 1 summarizes the flowchart of this study.

The pregnant women who agreed to participate in the research went through an initial anamnesis. At the time, they were asked about the presence and intensity of pain in the spine, which was measured by the visual analogue pain scale, as well as about urinary control and possible episodes of urgency, urge-incontinence and urinary losses on exertion. Gestational age was calculated from the date of the last menstrual period.

The assessment procedures included the postural assessment form to ascertain 


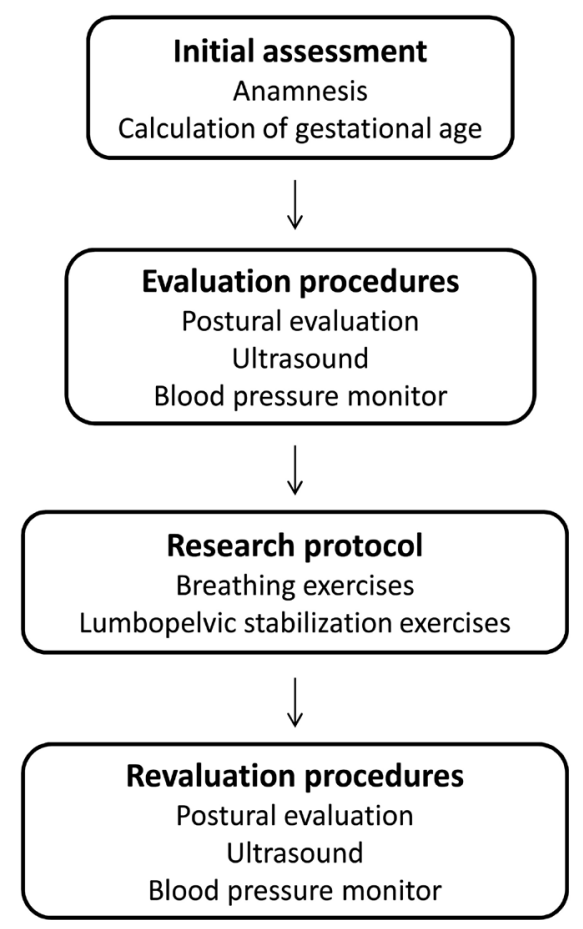

Figure 1. Research steps.

the alignment of the lumbar and pelvic segments by leveling the anterior and superior iliac spines, the ultrasound assessment to check the diaphragmatic thickness and mobility and to check the inspiratory and expiratory pressures using manovacuometer. Such procedures were performed before the first and after the last treatment session.

The diaphragm thickness was assessed using the B-mode and the M-mode, always with the volunteer lying in the supine position. Diaphragmatic mobility was assessed by both modes and thickness in inspiration and exhalation through mode $B$.

For B-mode, the diaphragmatic hemicupulas were accessed intercostally, with a $7-18 \mathrm{MHz}$ multifrequency linear transducer positioned in the longitudinal plane on the anterior axillary line, between the $7^{\circ}-8^{\circ}$ or $8^{\circ}-9^{\circ}$ intercostal spaces. The measurement site was the area where the diaphragm was affixed with the rib cage and the structure visualized between the parietal pleura and the peritoneal membrane. Three measurements of muscle thickness were performed during the maximum inspiration and expiration maneuvers, calculating the simple average for each maneuver. The fraction of diaphragmatic thickening (EDF) (inspiration thickness - expiration thickness/expiration thickness $\times 100$ )\% was calculated, which quantifies the degree of muscle thickening from the functional residual capacity to the total lung capacity, using the average of the measurements (Zeltoune et al., 2017) [15].

In M-mode, the right hemicupula was accessed via the anterior sub-costal route, in the oblique plane, between the hemiclavicular and anterior axillary lines, and the left hemicupula via the intercostal route, in the middle axillary 
line, both with 2 - $5 \mathrm{MHz}$ convex transducer Diaphragm kinetic curves were acquired during three breathing maneuvers: silent breathing, deep breathing and sniffing maneuver (sniff test). For each maneuver, three waves and respective amplitudes were obtained, calculating the simple average of these measurements (Zeltoune et al., 2017) [15].

To evaluate the maximum inspiratory (Pimax) and expiratory (Pmax) pressures, an analog manovacuometer with a one-way valve on the MURENAS stretcher and model MRN $-150+150 \mathrm{cmH}_{2} \mathrm{O}$ was used.

Prior to the assessment, each volunteer received an explanation and was shown the use of the device to minimize collection errors. She was then instructed to sit comfortably in a chair with a back, supported spine and feet touching the ground, maintaining an approximate $90^{\circ}$ angle of the hip and knee. With the nose occluded by a nose clip, he should breathe through an oval mouthpiece of the manovacuometer, keeping it firmly connected to the mouth to prevent leakage of perioral air.

Pimax was measured at the end of a calm exhalation, at which point the volume of gas contained in the lungs corresponded to the functional residual capacity (MIPxCRF), and the MEPx at the end of a calm exhalation (PEmáxCRF). A minimum of 3 maneuvers were performed with an interval of one minute between them and only the stable maneuvers were recorded for at least 1 second without air leakage and with a variation of $10 \%$ between the values. The highest value obtained was selected for the final analysis (Souza RB., 2002) [16].

Each procedure was performed by a duly trained evaluator.

The volunteers were submitted to 12 individual physiotherapy sessions, performed 2 or 3 times a week, over 4 to 6 weeks. Breathing and lumbar-pelvic stabilization exercises were performed, all previously explained and demonstrated by the researcher, who was duly trained to conduct the treatment protocol.

Each session lasted about 60 minutes and started with training exercises for the indoor unit with a focus on lumbar and pelvic stabilization (Table 1).

In all predictions, the exercises were performed in the order presented above, in a single series, with the greatest possible motor precision and the number of repetitions that vary with the capacity and physical fitness of each pregnant woman, but limited to 12 repetitions. The question used to determine the maximum number of repetitions was the quality of the movement. Thus, the exercise was interrupted when a researcher identified compensations suggestive of muscle fatigue.

For their execution, a volunteer was instructed to maintain a natural breathing pattern, free from effort, so that on inspiration there was an increase in the transverse and anteroposterior diameters of the abdomen and chest and on expiration there was a reduction in these diameters.

For respiratory muscle training, the volunteers remained comfortably seated in a chair with a back, supported column and feet touching the ground, maintaining an approximate $90^{\circ}$ angle of the hip and knee with the feet resting on the 
Table 1. Protocol of training exercises of the internal unit.

\begin{tabular}{|c|c|}
\hline Exercise & Description \\
\hline $\begin{array}{l}\text { 1) Activation of } \mathrm{TA}^{1} \\
\text { and } \mathrm{MAP}^{2}\end{array}$ & $\begin{array}{l}\text { Voluntária deitada em } \mathrm{DD}^{3} \text { sobre a maca, joelhos flexionados e pés } \\
\text { apoiados com esfignomanômetro insuflado a } 40 \mathrm{mmHg} \text { sob uma } \\
\text { coluna lombar. Foi orientada a contrair, ao mesmo tempo, o TA e os } \\
\text { MAP. A diferença de pressão identificada no esfignomanômetro } \\
\text { deveria ser a menor possível, sugerindo então que o acionamento } \\
\text { estava correto e a coluna estável. }\end{array}$ \\
\hline 2) Simple bridge & $\begin{array}{l}\text { Volunteer lying in } \mathrm{DD}^{3} \text { on the stretcher, knees bent and feet supported. } \\
\text { She was instructed to raise the hip of the stretcher and return it to its } \\
\text { initial position. }\end{array}$ \\
\hline $\begin{array}{l}\text { 3) LL abduction } \\
\text { bridge }^{4}\end{array}$ & $\begin{array}{l}\text { Volunteer lying in } \mathrm{DD}^{3} \text { on the stretcher, knees flexed and wrapped in } \\
\text { an elastic band, feet supported. She was instructed to raise the hip } \\
\text { of the stretcher, slightly abduct the knees, adduct them and } \\
\text { return the pelvis to its initial position. }\end{array}$ \\
\hline $\begin{array}{l}\text { 4) LL aduction } \\
\text { bridge }{ }^{4}\end{array}$ & $\begin{array}{l}\text { Volunteer lying in DD3 on the stretcher, knees bent with rubber ball } \\
\text { between them, feet supported. She was instructed to raise the hip } \\
\text { of the stretcher, adduce her knees slightly (squeezing the ball) and } \\
\text { return her knees and pelvis to the initial position. }\end{array}$ \\
\hline 5) Belt dissociation & $\begin{array}{l}\text { Volunteer sitting on a Swiss ball with a diameter compatible with her } \\
\text { height and biotype. She was instructed to rotate the pelvis in one } \\
\text { direction and the scapular waist in the opposite direction, } \\
\text { alternating the sides. }\end{array}$ \\
\hline
\end{tabular}

Caption: ${ }^{1} \mathrm{TA}$ : transverse abdominal; ${ }^{2} \mathrm{MAP}$ : pelvic floor muscles; ${ }^{3} \mathrm{DD}$ : supine position; ${ }^{4} \mathrm{MMII}$ : lower limbs.

floor.

Threshold IMT was used for inspiratory muscle training (IMT) and Threshold PEP for expiratory muscle training (TME). The first has a closed valve with positive pressure, with a spring that produces an independent linear flow load, while the second has a closed valve whose opening is activated when the pressure generated by the patient is greater than the value established in the device. Three series were performed with 10 repetitions, with an initial load of $40 \%$ of the Pimax of each patient for the Threshold IMT and 40\% of the Pmax for the Threshold PEP (Fonseca et al., 2010) [17]. Such load was progressively increased during the treatment. The pace varied according to the comfort of each volunteer and the breaks were 1 minute.

\section{Results}

Ten pregnant women were eligible. Of these, two participated in all stages of the research and, therefore, were included in the final analysis. One pregnant woman $(\mathrm{n}=1)$ underwent 12 physical therapy sessions and the other $(\mathrm{n}=2)$ participated in 4 sessions.

Figure 2 shows the flow of pregnant women throughout the study.

The results will be presented in a descriptive way, and not in a statistical way, due to the small number of volunteers who completed the study. 


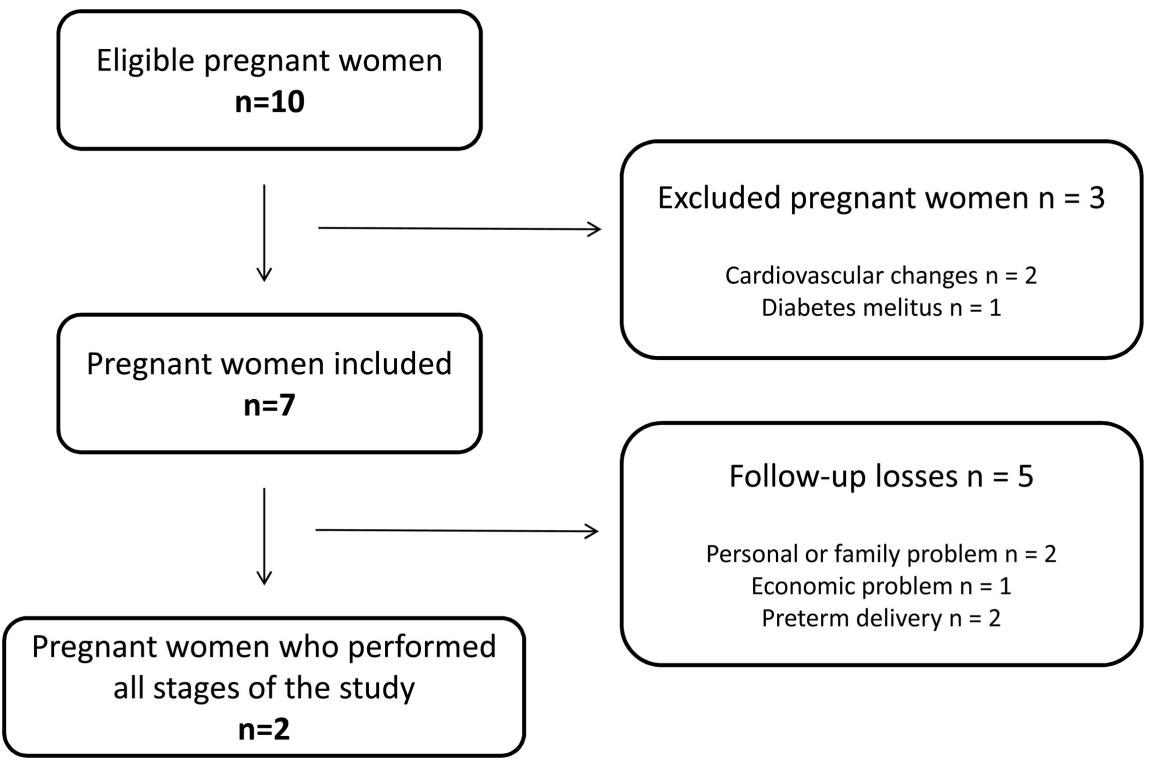

Figure 2. Flow of volunteers throughout the research.

\subsection{Sociodemographic Characteristics}

Volunteer 1 was 21 years old, graduated from college, was single but maintained a stable relationship. She was 27 weeks of gestational age from her first pregnancy and had a body mass index (BMI) of 19.9. Volunteer 2 was 33 years old and finished high school only. She was married, 25 weeks after her fourth pregnancy and had a BMI of 22.6.

\subsection{Outcomes Thickness and Diaphragmatic Mobility and Pimax and Pmax}

Ultrasound images showed increased mobility and thickness of the diaphragm at inspiration and exhalation, as shown in Table 2.

Pimax and Pmax, measured using manovacuometry, showed an increase in post-intervention values when compared to the initial evaluation (Table 3).

In the pre-intervention assessment, the volunteers reported a sensation of respiratory distress and dyspnea on exertion, even in those of small proportion, such as walking short distances, climbing a few steps and performing routine tasks at home. In the post-intervention assessment, both dyspnea and respiratory distress were reduced, according to reports.

\subsection{Outcomes Postural Alignment, Pain and Urinary Control}

Post-intervention postural assessment showed an increase in lumbar lordosis and abdominal volume consistent with advancing gestational age.

There was a report of a reduction in the sensation of low back pain according to VAS (pre- and post-intervention evaluation). For volunteer 1, the pain varied from 5 to 2 and from 6 to 2 , according to volunteer 2 .

In the initial assessment, the two volunteers reported episodes of urinary loss in activities such as coughing and faster walking. They also reported some 
Table 2. Variables of the ultrasound image, pre and post-intervention $(\mathrm{cm})$.

\begin{tabular}{ccccc}
\hline \multirow{2}{*}{ Variables } & \multicolumn{2}{c}{$\begin{array}{c}\text { Evaluation } \\
\text { pre-intervention }\end{array}$} & \multicolumn{2}{c}{$\begin{array}{c}\text { Evaluation } \\
\text { post-intervention }\end{array}$} \\
\cline { 2 - 5 } & $\mathrm{n}^{1}$ & $\mathrm{n2}^{2}$ & $\mathrm{n} 1$ & $\mathrm{n} 2$ \\
\hline Diaphragmatic mobility & 5.1 & 4.6 & 5.5 & 4.9 \\
Thickness at inspiration & 0.14 & 0.21 & 0.16 & 0.29 \\
Thickness at exhalation & 0.11 & 0.15 & 0.12 & 0.22 \\
FED $^{3}$ & $27 \%$ & $33 \%$ & $31 \%$ & $40 \%$ \\
\hline
\end{tabular}

Caption: ${ }^{1} \mathrm{n} 1$ : volunteer $1 ;{ }^{2} \mathrm{n} 2$ : volunteer $2 ;{ }^{3} \mathrm{FED}$ : diaphragmatic thickening fraction.

Table 3. Variables of manovacuometry, pre and post-intervention $\left(\mathrm{cmH}_{2} \mathrm{O}\right)$.

\begin{tabular}{ccccc}
\hline & \multicolumn{2}{c}{$\begin{array}{c}\text { Evaluation } \\
\text { pre-intervention }\end{array}$} & \multicolumn{2}{c}{$\begin{array}{c}\text { Evaluation } \\
\text { post-intervention }\end{array}$} \\
\cline { 2 - 5 } & $\mathrm{n} \mathbf{1}^{1}$ & $\mathrm{n2}^{2}$ & $\mathrm{n} 1$ & $\mathrm{n} 2$ \\
\hline Pimáx & -70 & -30 & -80 & -60 \\
Pemáx $^{3}$ & 50 & 50 & 70 & 70 \\
\hline
\end{tabular}

Caption: ${ }^{1} \mathrm{n} 1$ : volunteer $1 ;{ }^{2} \mathrm{n} 2$ : volunteer $2 ;{ }^{3} \mathrm{Pimax}$ : maximum inspiratory pressure; ${ }^{4} \mathrm{Pemax}$ : maximum expiratory pressure.

episodes of urinary urgency. Both effort losses and emergency situations were eliminated after the intervention period, according to reports.

\section{Discussion}

As the pregnancy progresses, uterine growth is expected to lead to reduced mobility and diaphragmatic thickness, culminating in a more apical breathing pattern associated with dyspnea on small efforts (Filho et al., 2013) [18]. In addition, there tends to be a reduction in MIP and PEMAX (Fonseca et al., 2010) [17].

There is evidence that inspiratory muscle training (IMT) improves ventilation in patients with chronic renal failure, heart disease and lung disease and that expiratory muscle training (TME) shows favorable results for some aspects of speech, swallowing, breathing and daily life activities that require production of adequate expiratory pressure (Sartor et al., 2015) [10].

The present study showed that the respiratory training performed through Threshold IMT and PEP resulted in increased mobility and thickness of the diaphragm on inspiration and exhalation and increased Pimax and Pmax. Such increases were positively expressed in the volunteers' routine, which reported reduced dyspnea on small efforts. However, the fact that no studies were found using threshold IMT and or PEP in a sample of pregnant women, made it impossible to discuss our results in the light of scientific evidence. Due to our results pointing to an improvement in respiratory dynamics through specific training in pregnant women, it would be appropriate.

No similar findings were found obtaining respiratory muscle training in preg- 
nant women, using the IMT and PEP threshold, so further studies related to the respective subject are needed.

With regard to postural alignment, an increase in lumbar lordosis and abdominal volume was observed, consistent with advancing gestational age, in the post and pre-intervention comparisons.

It is known that changes in the alignment of the spine mediated by the action of relaxin on the ligaments and uterine growth favor pain complaints, especially in the lumbosacral region, (Assis et al., 2012) [19] and overload in the pelvic floor muscles, resulting in often in difficulty in voiding control during pregnancy (Assis et al., 2012) [19]. The functional relationship between the muscles of the internal unit may explain why changes in the lumbar and pelvic alignment interfere with the functions of the lumbar muscles and the pelvic floor, so that better alignments tend to relate to lesser repercussions on the function of passive structures and active in this segment and, consequently, less complaints of urinary and anal incontinence, sexual dysfunction and lumbosacral discomfort (Silveira et al., 2018) [5].

The volunteers of this research, however, despite the increase in lumbar lordosis, reported that after the intervention period there was a reduction in the sensation of pain according to the VAS (pre- and post-intervention evaluation). For volunteer 1, the pain varied from 5 to 2 and from 6 to 2, according to volunteer 2 . They also reported a reduction in urinary urgency episodes and urinary losses on exertion. These results can be explained by the stabilization training of the muscles that cross the lumbar and pelvic segments, which act predominantly in an eccentric way during static positions and controlled movements of extremities (France et al., 2008 [12]; Silveira et al., 2018 [5]) in order to stabilize the trunk (Bliven et al., 2013) [20], reducing overload and tissue stress related to pain complaints.

The methodological design of the present study associated with the small sample size does not allow us to make inferences for the general population of pregnant women. However, its relevance lies in the lack of publications on respiratory muscle training and internal unit in pregnant women and its effects on the diaphragm and on the stability of the lumbar spine. For this reason, the results of this research contribute to fill an important scientific gap and increase the body of knowledge regarding physical therapy intervention during pregnancy, more specifically with a focus on respiratory function and lumbar and pelvic alignment.

\section{Conclusions}

The results of the present study allow us to conclude that the respiratory muscle training associated with the training of the internal unit had a positive impact on the thickness and diaphragmatic mobility, as well as on the lumbar stability of the two pregnant women who completed all stages of this research. These results may explain the volunteers' report about the reduction of respiratory discomfort 
during activities of daily living and urinary losses, even by increasing lumbar lordosis and abdominal volume.

Due to the small sample size, it is suggested that the respiratory training and lumbar and pelvic stabilization protocol used be replicated in randomized clinical trials with samples of expressive size so that the results presented here are corroborated or refuted, in order to better substantiate the physiotherapist's clinical practice in scientific evidence.

\section{Conflicts of Interest}

The authors declare no conflicts of interest regarding the publication of this paper.

\section{References}

[1] Constantine, M.M. (2014) Physiologic and Pharmacokinetic Changes in Pregnancy. Frontiers in Pharmacology, 5, Article No. 65. https://doi.org/10.3389/fphar.2014.00065

[2] Jensen, D., Webb, K.A., Davies, G.A.L. and O’Donnelllnda, D.E. (2008) Mechanical Ventilator Constraints during Incremental Cycle Exercise in Human Pregnancy: Implications for Respiratory Sensation. The Journal of Physiology, 586, 4735-4750. https://doi.org/10.1113/jphysiol.2008.158154

[3] Metha, M.D., Chen, K., Hard, K. and Powrie, R. (2015) Respiratory Disease in Pregnancy. Best Practice \& Research: Clinical Obstetrics \& Gynaecology, 29, 598-611. https://doi.org/10.1016/j.bpobgyn.2015.04.005

[4] Panjabi, M.M. (1992) The Stabilizing System of the Spine, Part 1: Function, Dysfunction, Adaption and Enhancement. Journal of Spinal Disorders, 5, 383-389. https://doi.org/10.1097/00002517-199212000-00001

[5] Silveira, A.P.B., Nagel, L.Z., Pereira, D.D., Morita, A.K., Spinoso, D.H., Navega, M.T. and Marques, N.R. (2018) Immediate Effect of a Method Training Session. Pilates on the Pattern of Co-Contraction of Trunk Stabilizing Muscles in Individuals with and without Chronic Nonspecific Low Back Pain. Fisioterapia e Pesquisa, 25, 172-181. https://doi.org/10.1590/1809-2950/17594425022018

[6] Lemos, A., Souza, A.L., Andrade, A.D., Figueiroa, J.N. and Cabral-Filho, J.E. (2011) Respiratory Muscle Strength: Comparison between Primiparous and Nulliparous. Jornal Brasileiro de Pneumologia, 37, 193-199. https://doi.org/10.1590/S1806-37132011000200009

[7] Marcos, I.A.C.G. (2007) Lung and Pregnancy. Revista Portuguesa de Pneumologia, 13, 213-237. https://doi.org/10.1016/S0873-2159(15)30345-7

[8] Onaga, F.I., Jamami, M., Ruas, G., Di Lorenzo, V.A.P. and Jamami, L.K. (2010) Influence of Different Types of Nozzles and Tracheal Diameters on Manovacuometry. Fisioterapia em Movimento, 23, 211-219. https://doi.org/10.1590/S0103-51502010000200005

[9] Souchard, E. (1980) The Diaphragm. 3rd Edition, Summus Editorial, São Paulo.

[10] Sartor, M.M., Sola, A.G., Depolo, M., Duarte, E., Rodríguez, D.A., Barrera, M.C. Barreiro, E., Escalada, F., Levi, M.O. and Marco, E. (2015) Inspiratory and Expiratory Muscle Training in Subacute Stroke: A Randomized Clinical Trial. Neurology, 85, 564-572. https://doi.org/10.1212/WNL.0000000000001827 
[11] Urquhart, D.M., Barker, P.J., Hodges, P.W., Story, I.S. and Briggs, C.A. (2005) Regional Morphology of the Transversus Abdominis and Obliquus Internus and Externus Abdominis Muscles. Clinical Biomechanics, 20, 233-241.

https://doi.org/10.1016/j.clinbiomech.2004.11.007

[12] França, F.J.R., Burke, T.N., Claret, D.C. and Marques, A.P. (2008) Segmental Stabilization of the Lumbar Spine in Low Back Pain: A Literature Review and an Exercise Program. Fisioterapia e Pesquisa, 15, 200-206.

https://doi.org/10.1590/S1809-29502008000200015

[13] Stenes, V.K., Coorevits, P.L., Bouche, K.G., Mahieu, N.N., Vanderstraeten, G.G. and Danneels, L.A. (2007) The Influence of Specific Training Trunk Muscle Recruitment Patterns in Healthy Subjects during Stabilization Exercises. Manual Therapy, 12, 271-279. https://doi.org/10.1016/j.math.2006.07.009

[14] Metring, N.L., Cruz, F.C.A., Takaki, M.R. and Carbone, E.S.M. (2014) Effects of Physical Therapy Techniques Using Respiratory Mechanics on the Pelvic Floor: Systematic Review. Revista Fisioterapia \& Saúde Funcional, 3, 23-32.

[15] Zeltoune, R., Koifman, Fong, M.S. and Mogami, R. (2017) Letters to the Editor. Radiologia Brasileira, 50, 405-415. https://doi.org/10.1590/0100-3984.2016.0072

[16] Souza, R.B. (2002) Maximum Static Respiratory Pressures. Jornal Brasileiro de Pneumologia, 28, S155-S165.

[17] Fonseca, M.A., Cader, S.A., Dantas, E.H.M., Bacelar, S.C., Silva, E.B. and Leal, S.M.O (2010) Respiratory Muscle Training Program: Impact on Functional Autonomy of the Elderly. Revista da Associação Médica Brasileira, 56, 642-648.

https://doi.org/10.1590/S0104-42302010000600010

[18] Filho, J.M., Menossi, B.R.S., Preis, C., Neto, L.B. and Neto, A.S. (2013) Analysis of Lumbopelvic Stabilizing Musculature in Young People with and without Low Back Pain. Fisioterapia em Movimento, 26, 587-594. https://doi.org/10.1590/S0103-51502013000300012

[19] Assis, T.R., Sá, A.C.A.M., Amaral, W.N., Batista, E.M., Formiga, C.K.M.R. and Conde, D.M. (2013) Effect of an Exercise Program to Strengthen the Pelvic Floor Muscles of Multiparous Women. Revista Brasileira de Ginecologia e Obstetrícia, 35, 10-15. https://doi.org/10.1590/S0100-72032013000100003

[20] Bliven, K.C.H. and Anderson, B.E. (2013) Core Stability Training for Injury Prevention. Sports Health, 5, 514-522. https://doi.org/10.1177/1941738113481200 